\title{
Work environment and low back pain: the influence of occupational activities
}

National Institute of Occupational Health, Lersø Parkallé 105, DK-2100, Copenhagen Ø, Denmark

Y Xu

E Bach

E Ørhede

Correspondence to: Dr Elsa Bach, National Institute of Occupational Health, Lersø Parkallé 105, DK-2100, Copenhagen $\emptyset$, Denmark.

\author{
Ying $\mathrm{Xu}$, Elsa Bach, Elsa Ørhede
}

\begin{abstract}
Objectives- To find associations between the prevalence of low back pain and occupational activities.

Methods-Interviews of a random sample of 5185 19-59 year old Danish employees analysed by logistic regression.

Results-Increased risks of low back pain were found for "vibration affecting the whole body" (odds ratio $(O R)=1.28$ ), "physically hard work" (OR=1.28), "frequently twisting or bending" (OR=1.71), "standing up" (OR=1.20), and "concentration demands" $(O R=1.28)$. In the analysis of dose-response relations between low back pain and the risk factors, the one year period prevalence increased with increasing exposure time during a working day to each of the risk factors. The prevalence proportion ratio for those reporting to be exposed for most of the working time were 1.30 for vibrations affecting the whole body, 1.54 for physically hard work, 1.48 for frequently twisting or bending, 1.29 for standing up, and 1.13 for concentration demands. These associations seemed to be stronger in the subset of subjects who worked for 37 hours or more per week. The population attributable fractions were $\mathbf{1 5 . 1 \%}$ for frequently twisting or bending, $15.0 \%$ for standing up, $7.6 \%$ for concentration demands, and $\mathbf{4 . 4 \%}$ for physically hard work.

Conclusion-Vibrations affecting the whole body, physically hard work, frequently twisting or bending, standing up, and concentration demands proved to be risk factors for the occurrence of low back pain, even after controlling for age, sex, educational level, and duration of employment in a specific occupation.
\end{abstract}

(Occup Environ Med 1997;54:741-745)

Keywords: low back pain; occupational activity; attributable risk

Low back pain is a major cause of disability among the working population and has a significant socioeconomic impact. ${ }^{1-4}$ To identify occupational risk factors for low back pain many investigators have examined the effects of occupational activities on the occurrence of low back pain. ${ }^{5-11}$ A review of the literature showed that results regarding effects of factors such as lifting heavy loads and driving motor vehicles were fairly consistent, ${ }^{356912-16}$ indicating that exposure to these factors increased the risk of low back pain. For factors such as sedentary work or physically hard work, the results were inconsistent. ${ }^{24}{ }^{17-20}$ Risks of low back pain related to other occupational factors were not well measured. Surveys have rarely examined the dose-response relation between the risk factors and low back pain.

The main objectives of this study were: (a) to identify occupational activities associated with low back pain; $(b)$ to measure the risks of low back pain for different individual activities and explore some possible dose-response relations.

\section{Methods}

This study was based on reanalysis of a Danish survey among Danish employees. The survey was a nationwide cross sectional survey conducted from October to December 1990. A random sample of $970018-59$ year old people was drawn from the Danish population and 8664 of them (response rate $89.3 \%$ ) agreed to be interviewed. The data were collected by telephone interview with a structured questionnaire. Of the respondents 5940 people were employed at the time of the interview or had been employed up to two months before. These respondents were interviewed in detail about working conditions.

A total of 15 variables have been analysed in this paper including age, sex, educational level, duration of employment in a specific occupation, weekly work time, status of exposure to certain occupational activities, and symptoms of low back pain. Only those who had been employed in a specific occupation for at least one year were included in this study. Thus, the actual applied sample consisted of 5185 subjects with the same age, sex, and occupational distributions as in the Danish population. We have described this sample and the prevalences for low back pain in different occupational groups in an earlier published study. ${ }^{21}$

Subjects with missing responses were excluded from the analyses of the corresponding variables.

Subjects were classified as being with or without low back pain during the previous year from their answers to the question "Have you at any time during the past 12 months had symptoms of your low back?" Positive respondents were the cases in the analyses. The symptoms were defined as all conditions of pain, ache, or discomfort localised in the lower back, regardless of intensity and severity.

Ten different occupational exposures were examined in this study. They were "vibrations affecting the whole body", "physically hard 
Table 1 Adjusted ORs (95\% CI) and prevalence of low back pain by risk factors

\begin{tabular}{|c|c|c|c|c|c|}
\hline \multirow[b]{2}{*}{ Risk factor } & \multicolumn{3}{|c|}{ Full model } & \multicolumn{2}{|c|}{ Reduced model } \\
\hline & $O R$ & Pvalue & $\begin{array}{l}\text { Prevalence } \\
(\%)\end{array}$ & $O R$ & $(95 \% C I)$ \\
\hline $\begin{array}{l}\text { Vibrations affecting the whole } \\
\text { body }\end{array}$ & 123 & 0122 & 570 & 120 & 1100 to 16 \\
\hline Physically hard work ${ }^{\star}$ & 1.27 & 0.013 & 14.0 & 1.28 & (1.08 to 1.52$)$ \\
\hline Frequently twisting or bending ${ }^{\star}$ & 1.73 & 0.000 & 40.2 & 1.71 & (1.51 to 1.93$)$ \\
\hline Sitting down ${ }^{\star}$ & 0.84 & 0.016 & 62.8 & 0.84 & $(0.74$ to 0.96$)$ \\
\hline Standing up ${ }^{\star}$ & 1.18 & 0.058 & 73.7 & 1.20 & (1.04 to 1.38$)$ \\
\hline Walking a lot ${ }^{\star}$ & 1.05 & 0.586 & 70.0 & & \\
\hline Working with hands raised ${ }^{\star}$ & 1.00 & 0.976 & 15.5 & & \\
\hline Concentration demands ${ }^{\star}$ & 1.31 & 0.001 & 82.1 & 1.28 & (1.10 to 1.48$)$ \\
\hline Repetition* ${ }^{\star}$ & 1.02 & 0.740 & 44.4 & & \\
\hline Heavy lifting* & 1.06 & 0.552 & & & \\
\hline Sex (male) & 0.86 & 0.025 & & 0.84 & (0.75 to 0.95$)$ \\
\hline Age & 1.02 & 0.575 & & & \\
\hline Educational level & 0.98 & 0.462 & & & \\
\hline $\begin{array}{l}\text { Years of employment in current } \\
\text { occupation }\end{array}$ & 1.01 & 0.811 & & & \\
\hline
\end{tabular}

* Risks were calculated for each factor the subjects who reported exposure to a specific factor at least $1 / 4$ of the working time per day relative to those who were never or seldom exposed to the corresponding factor. between those with a risk factor and those without. Then population attributable risk was obtained by multiplying the attributable risk with the prevalence of the risk factor. Lastly the population attributable fraction was determined by the population attributable risk divided by the one year prevalence of low back pain.

Statistical analyses were carried out with the SPSS/PC (Statistical Program for Social Sciences for the Personal Computer) package, version 4.0.1. All tests made were two sided and the level of significance was chosen as $5 \%$.

\section{Results}

IDENTIFICATION OF RISK FACTORS

Six occupational exposures were significantly associated with the occurrence of low back pain. Table 1 shows the odds ratios (ORs) for low back pain in relation to all occupational exposures. Five significantly increased risks of low back pain were found: for physically hard work $(\mathrm{OR}=1.28)$, frequently twisting or bending $(O R=1.71)$, standing up $(O R=1.20)$, and concentration demands $(\mathrm{OR}=1.28)$, whereas a decreased risk was found for sitting down $(O R=0.84)$. The risk factor vibrations affecting the whole body was very close to significance $(P=0.052)$ and was included in the reduced model in table 1. For other occupational exposures - for example, walking a lot, working with hands raised, and repetition-all ORs of low back pain were above one, but they were not significant. Also, there was a significant covariate included in the model. It was sex with a lower risk of low back pain for men $(\mathrm{OR}=0.84)$.

\section{EFFECTS OF MULTIPLE RISK FACTORS}

To assess a comprehensive effect of multiple risk factors on low back pain we compared subjects exposed to all five risk factors (high risk group) with those reporting never or seldom exposure to any risk factor (low risk group). As sex was significantly associated with low back pain in the multivariate analysis the examination was made by a stratified analysis to control for any confounding effect arising from differences between the two sexes. In the low risk group the prevalences of low back pain were $19 \%(n=64)$ and $21 \%(n=62)$ respectively for men and women, whereas the high risk group had the corresponding prevalences of $63 \%(n=54)$ and $57 \%(n=7)$. The crude ORs were 3.4 (95\% confidence interval $(95 \% \mathrm{CI})$ 1.94 to 5.82 ) and 2.7 (95\% CI 1.22 to 6.08 ) for men and for women, respectively. Calculated from the logistic regression model the high risk group had an OR of $3.6(1.28 \times 1.28 \times 1.71 \times$ 1.28) compared with the low risk group.

DOSE-RESPONSE RELATION OF THE RISK FACTORS When the quantity of exposure was considered as measured with a five point scale according to the proportion of time exposed in the working day, associations of the five risk factors with low back pain became more apparent (table 2). In each analysis, there was a significant trend towards a greater prevalence of low back pain with a greater proportion of the day exposed to 
Table 2 Number of subjects, one year prevalence, the prevalence proportion ratios (PPR), ORs of low back pain by proportion of time exposed to occupational factors in the working day, and $P$ value for significance of trends

\begin{tabular}{|c|c|c|c|c|c|}
\hline Risk factor & $n$ & Prevalence (\%) & $P P R$ & $O R$ & $P$ value \\
\hline \multicolumn{6}{|c|}{$\begin{array}{l}\text { Vibrations affecting the whole } \\
\text { body: }\end{array}$} \\
\hline No or seldom & 4888 & 42.6 & 1 & & \\
\hline $1 / 4$ of the time & 101 & 52.5 & 1.23 & 1.60 & \\
\hline $1 / 2$ of the time & 63 & 44.4 & 1.04 & 1.17 & \\
\hline $3 / 4$ of the time & 34 & 41.2 & 0.97 & 1.00 & \\
\hline All of the time & 96 & 55.2 & 1.30 & 1.78 & \\
\hline Total & 5182 & & & & 0.009 \\
\hline \multicolumn{6}{|c|}{ Physically hard work: } \\
\hline No or seldom & 4456 & 41.2 & 1 & & \\
\hline $1 / 4$ of the time & 357 & 47.9 & 1.16 & 1.34 & \\
\hline $1 / 2$ of the time & 195 & 60.5 & 1.47 & 2.26 & \\
\hline $3 / 4$ of the time & 75 & 60.0 & 1.46 & 2.21 & \\
\hline All of the time & 98 & 63.3 & 1.54 & 2.51 & \\
\hline Total & 5181 & & & & 0.000 \\
\hline \multicolumn{6}{|c|}{ Frequently twisting or bending: } \\
\hline No or seldom & 3099 & 36.5 & 1 & & \\
\hline $1 / 4$ of the time & 491 & 50.9 & 1.39 & 1.79 & \\
\hline $1 / 2$ of the time & 578 & 52.2 & 1.43 & 1.88 & \\
\hline $3 / 4$ of the time & 291 & 54.0 & 1.48 & 2.00 & \\
\hline All of the time & 720 & 54.0 & 1.48 & 2.02 & \\
\hline Total & 5179 & & & & 0.000 \\
\hline \multicolumn{6}{|l|}{ Standing up: } \\
\hline No or seldom & 1363 & 36.6 & 1 & & \\
\hline $1 / 4$ of the time & 1035 & 42.9 & 1.17 & 1.31 & \\
\hline $1 / 2$ of the time & 1022 & 44.3 & 1.21 & 1.40 & \\
\hline $3 / 4$ of the time & 532 & 47.7 & 1.30 & 1.61 & \\
\hline All of the time & 1225 & 47.1 & 1.29 & 1.55 & \\
\hline Total & 5177 & & & & 0.000 \\
\hline \multicolumn{6}{|c|}{ Concentration demands: } \\
\hline No or seldom & 928 & 39.7 & 1 & & \\
\hline $1 / 4$ of the time & 373 & 44.8 & 1.13 & 1.24 & \\
\hline $1 / 2$ of the time & 736 & 40.5 & 1.02 & 1.04 & \\
\hline $3 / 4$ of the time & 874 & 42.9 & 1.08 & 1.14 & \\
\hline All of the time & 2265 & 44.9 & 1.13 & 1.24 & \\
\hline Total & 5176 & & & & 0.007 \\
\hline
\end{tabular}

the risk factor. For the risk factors vibrations affecting the whole body and concentration demands the trends were less pronounced. For these two risk factors the prevalences in groups exposed for a quarter of the time or more were higher than in groups never or seldom exposed.

Compared with those reporting never or seldom exposure to a specific risk factor the one year period prevalence of low back pain for employees reporting to be exposed most of the working time to the corresponding factors increased separately from $43 \%$ to $55 \%$ for vibration affecting the whole body, from $41 \%$ to $63 \%$ for physically hard work, from $37 \%$ to $54 \%$ for frequently twisting or bending, from $37 \%$ to $47 \%$ for standing up, and from $40 \%$ to $45 \%$ for concentration demands, with corresponding prevalence proportion ratios of 1.30 , $1.54,1.48,1.29$, and 1.13 .

The proportions of time exposed during the working day was used to reflect the quantity of exposure, which is necessarily related to the duration of working time per day, We also examined the effect of working time on the relation between exposure to a specific factor and low back pain (table 3). We found that the associations tended to be stronger for those subjects who were required to work for more than 37 hours a week (long working time group). For example, in the long working time group, the prevalence proportion ratio for employees reporting exposure to all the risk factors were respectively 1.25 for vibrations affecting the whole body, 1.60 for physically hard work, 1.52 for frequently twisting or bending, 1.29 for standing up, and 1.14 for concentration demands compared with people reporting never or seldom exposure. For people with less than 37 hours of weekly working time (short working time group) the corresponding prevalence proportion ratios were $1.78,1.32,1.35,1.25$, and 1.12. Furthermore, the dose-response relations for the risk factors were more distinct in the long working time group (table 3).

\section{ESTIMATION OF ATTRIBUTABLE RISK}

Table 4 shows the estimated attributable risks, population attributable risks, and attributable fractions for each of the five risk factors. According to the magnitude of the population attributable fractions (from great to less) they were $15.2 \%$ for frequently twisting or bending, $14.9 \%$ for standing up, $7.8 \%$ for concentration demands, $4.4 \%$ for physically hard work, and $1.0 \%$ for vibration affecting the whole body. On a national employee basis approximately $345000,341000,183000,99000$, and 22500 cases, respectively, were related to these risk factors.

\section{Discussion}

This paper deals with a health phenomenon that is common even among unexposed people. The symptoms are prevalent and the time of onset is difficult to determine.

Our data indicate that the occupational exposures including vibrations affecting the whole body, physically hard work, frequently twisting or bending, standing up, and concentration demands are risk factors for low back pain. This finding, except for the factor of concentration demands, is consistent with those of several other studies. ${ }^{2} 7_{1011} 1122-24$ More items describing demands at work have been shown to be associated with low back pain, ${ }^{25}$ but in this study we only have information on concentration demands. No firm conclusion concerning this potential risk factor have been drawn before due to lack of information. Our results therefore contribute to this by indicating an association.

In this study we found that women had a higher prevalence of low back pain than men. In studies that focus on selected occupations it was found that men and women have the same prevalence or that men have higher prevalence than women. ${ }^{26}$ However, our results in this population based study are consistent with another Danish population based study. ${ }^{27}$

Furthermore, as this is an analytical study of low back pain in a large population of employees in which the dose-response relations between occupational risk factors and low back pain have been estimated as well as the estimated attributable risk or population attributable fraction for each of the risk factors. Our data may help to measure the magnitude of the effects of the specific factors on the risk of low back pain, and suggest that the associations of the risk factors with low back pain are stronger among those who are required to have worked for 37 hours or more a week. To our knowledge this is a novel finding.

Population attributable fraction is an important concept and measure in public health. It 
Table 3 Number of subjects, one year prevalence of low back pain for two categories of weekly working time by proportion of the working day exposed to occupational risk factors

\begin{tabular}{|c|c|c|c|c|c|c|}
\hline \multirow[b]{2}{*}{ Risk factor } & \multicolumn{3}{|c|}{$<37$ hours/week } & \multicolumn{3}{|c|}{$\geqslant 37$ hours/week } \\
\hline & $n$ & Prevalence ${ }^{\circ}$ & Pvalue & $n$ & Prevalence \% & Pvalue \\
\hline \multicolumn{7}{|c|}{$\begin{array}{l}\text { Vibrations affecting the } \\
\text { whole body: }\end{array}$} \\
\hline No or seldom & 1152 & 44.9 & & 3736 & 41.9 & \\
\hline $1 / 4$ of the time & 7 & 28.6 & & 94 & 54.3 & \\
\hline $1 / 2$ of the time & 4 & 25.0 & & 59 & 45.8 & \\
\hline $3 / 4$ of the time & 5 & 40.0 & & 29 & 41.4 & \\
\hline All the time & 10 & 80.0 & & 86 & 52.3 & \\
\hline Total & 1178 & & 0.584 & 4004 & & 0.007 \\
\hline \multicolumn{7}{|c|}{ Physically hard work: } \\
\hline No or seldom & 1020 & 43.4 & & 3436 & 40.5 & \\
\hline $1 / 4$ of the time & 75 & 49.3 & & 282 & 47.5 & \\
\hline $1 / 2$ of the time & 44 & 52.3 & & 151 & 62.9 & \\
\hline $3 / 4$ of the time & 17 & 88.2 & & 58 & 51.7 & \\
\hline All the time & 21 & 57.1 & & 77 & 64.9 & \\
\hline Total & 1177 & & 0.003 & 4004 & & 0.000 \\
\hline \multicolumn{7}{|c|}{$\begin{array}{l}\text { Frequently twisting or } \\
\text { bending: }\end{array}$} \\
\hline No or seldom & 653 & 39.5 & & 2446 & 35.7 & \\
\hline $1 / 4$ of the time & 134 & 48.5 & & 357 & 51.8 & \\
\hline $1 / 2$ of the time & 139 & 57.6 & & 439 & 50.6 & \\
\hline $3 / 4$ of the time & 81 & 44.4 & & 210 & 57.6 & \\
\hline All the time & 170 & 53.5 & & 550 & 54.2 & \\
\hline Total & 1177 & & 0.000 & 4002 & & 0.000 \\
\hline \multicolumn{7}{|l|}{ Standing up: } \\
\hline No or seldom & 299 & 39.5 & & 1064 & 35.8 & \\
\hline $1 / 4$ of the time & 220 & 45.9 & & 815 & 42.1 & \\
\hline $1 / 2$ of the time & 204 & 43.6 & & 818 & 44.5 & \\
\hline $3 / 4$ of the time & 131 & 46.6 & & 401 & 48.1 & \\
\hline All the time & 323 & 49.5 & & 902 & 46.2 & \\
\hline Total & 1177 & & 0.017 & 4000 & & 0.000 \\
\hline \multicolumn{7}{|c|}{ Concentration demands: } \\
\hline No or seldom & 244 & 42.2 & & 684 & 38.7 & \\
\hline $1 / 4$ of the time & 78 & 41.0 & & 295 & 45.8 & \\
\hline $1 / 2$ of the time & 146 & 42.5 & & 590 & 40.0 & \\
\hline $3 / 4$ of the time & 195 & 45.6 & & 679 & 42.1 & \\
\hline All the time & 515 & 47.4 & & 1750 & 44.2 & \\
\hline Total & 1178 & & 0.108 & 3959 & & 0.026 \\
\hline
\end{tabular}

expresses the proportion of cases in the population related to a particular risk factor. Unlike the relative risk it depends not only on strength of the association between the risk factor and a disease but also on the prevalence of the risk factor. Therefore, from the point of view of public health, population attributable fraction can provide more comprehensive information on the risk of low back pain related to a risk factor. A risk factor with a small relative risk can still have a large attributable fraction if it has a high prevalence. This importance of population attributable fraction is reflected by our data. For instance, table 1 shows that standing up, as one of the risk indicators for the occurrence of low back pain, has a relatively lower OR (1.20) than that of physically hard

Table 4 Estimated attributable risks and population attributable fractions based on 12 month prevalences (\%) by occupational risk factor

\begin{tabular}{llll}
\hline Risk factor & $\begin{array}{l}\text { Attributable } \\
\text { risk }\end{array}$ & $\begin{array}{l}\text { Population } \\
\text { attributable } \\
\text { risk }\end{array}$ & $\begin{array}{l}\text { Population } \\
\text { attributable } \\
\text { fraction }\end{array}$ \\
\hline $\begin{array}{l}\text { Vibrations } \\
\text { affecting the } \\
\text { whole body }\end{array}$ & 7.7 & 0.4 & 1.03 \\
$\begin{array}{c}\text { Physically hard } \\
\text { work }\end{array}$ & 13.5 & 1.9 & 4.4 \\
$\begin{array}{c}\text { Frequently } \\
\text { twisting or }\end{array}$ & 16.3 & 6.5 & 15.2 \\
$\quad$ bending & 8.7 & 6.4 & 14.9 \\
$\begin{array}{c}\text { Standing up } \\
\text { Concentration } \\
\text { demands }\end{array}$ & 4.1 & 3.3 & 7.8 \\
\hline
\end{tabular}

work (1.29), frequently twisting or bending (1.70), and concentration demands (1.31). But its population attributable fraction $(15.0 \%)$ (table 4) was much higher than that of physically hard work $(4.4 \%)$ or concentration demands $(7.6 \%)$. It must be stressed that in the estimation of attributable risk or population attributable fraction we have used prevalence instead of incidence although these measures are classically defined in terms of incidence rather than prevalence. The reason for this is that the incidence is difficult to measure correctly as low back pain is usually recurrent or follows a chronic course with exacerbation, and the original data did not allow a calculation of incidence in any form. Furthermore, we assume that duration and strength of low back pain in the exposed and the unexposed groups are of the same magnitude but we cannot document the likelihood of this assumption. People with long lasting and severe symptoms may tend to disappear from the exposure. This selection bias will lead to low risk estimates.

The status of exposure to occupational factors was ascertained by self reporting and there was no reliable standard against which we could assess the accuracy of the reports. Questionnaires are often the method of choice for assessing exposure data because no other source of information is available, or because they allow a larger study size with greater statistical power than would be possible with other more accurate measurement techniques. ${ }^{2 *}$ Validity studies have shown that measurement of exposure in self administered questionnaires is rather unreliable and should be restricted to dichotomous registrations ${ }^{20}$ (table 1). However, the same authors have shown that measurement is more reliable in personal interviews as in this study, ${ }^{30}$ and measurement is therefore used in tables 2 and 3.

As the original survey from which our data were obtained was cross sectional it is impossible to confirm whether the associations found were causal. Therefore, it is difficult to determine whether the subjects had modified activities or occupational demands because they had symptoms of low back pain-for example, in the literature heavy lifting is one of the most consistent factors associated with low back pain. 5691214

A high prevalence of back disorders is usually found in jobs involving frequent heavy lifting, ${ }^{17}{ }^{21} 31$ whereas a moderate amount of lifting is not thought to cause back symptoms. ${ }^{+17}=$ A moderate amount of lifting was not significant in our data perhaps because of the interaction between the risk factor heavy lifting and low back pain. ${ }^{32}$ People with severe low back pain may have changed to an occupation with less heavy lifting or may even have left the labour market because they were unable to do the heavy lifting. Especially if they have moved to occupations with no heavy lifting and still have their low back pain our estimates of the relative risk gets too low. We have tried to reduce this bias by excluding people who have been in their present job for less than one year. It might also be due to the fact that heavy lift- 
ing reported in a general survey may be less heavy than heavy lifting reported from selected occupations in which it is a frequent work task and so the criteria for reporting it are higher. This may lead to low risk estimates.

On the other hand it is possible that people with low back pain will tend to report higher exposures because the low back pain helps them remember the heavy lifting better or because people without low back pain tend to forget the exposure. ${ }^{32}{ }^{33}$ This recall bias leads to high risk estimates. In our study we have tried to minimise the recall bias by interviewing the respondents about exposures and health effects independently and by asking about many risk factors and many health effects in the same interview. The trend seen in the dose-response analyses for some of the other risk factors indicates that we have succeeded to some extent.

In this study other exposures involving sitting down, walking a lot, working with hands raised, and repetition, were not associated with increased risks of the occurrence of low back pain. By contrast, sitting down was associated with a significantly decreased risk. This finding is contradictory to that of other studies, although whether such a work posture is a risk indicator for low back pain is still an open question. ${ }^{211} 1734$ No reasonable explanation has been found for this association. Nevertheless, a supported sitting posture and changing a person's work posture are important factors in reducing burdens on the spine and decreasing posture fatigue, as suggested in several previous studies. ${ }^{11181935}$ When the effect of sitting is examined it should be noted if the sitting was supported and whether a change in work posture was required. Unfortunately, no such information was provided in our data. Accordingly further investigations are needed to test the association.

Finally, it should be emphasised again that this large population based study has estimated the risks of low back pain in relation to the specific occupational exposure in both the analysis of dose-response relations and the estimations of attributable risk and population attributable fraction. A follow up study conducted in 1995-6 will provide us with even better estimates of attributable risk and population attributable fraction compared with the estimates in the present cross sectional study.

This study is based on data from a Danish survey concerning employees. The survey was conducted in collaboration with the Danish National Institute of Social Research.

1 Andersson GBJ. Low back pain in industry: epidemiological aspects. Scand $\mathcal{F}$ Rehab Med 1979;11:163-8.

2 Frymoyer JW, Pope MH, Costanza MC, Rosen JC, Goggin JE, Wilder DG. Epidemiological studies of low-back pain. Spine 1980;5:419-23.

3 Frymoyer JW, Pope MH, Clements JH, Wilder DG, MacPherson B, Ashikaga T. Risk factors in low back pain: an epidemiologic survey. $\mathscr{f}$ Bone foint Surg Am 1983;65: an epidem.

4 Kelsey JL. An epidemiological study of acute herniated lumbar intervertebral disc. Rheumatol Rehabil 1975;14: 144-55.
5 Walsh K, Varnes N, Osmond C, Styles R, Coggon D. Occupational causes of low-back pain. Scand $\mathcal{f}$ Work Environ Health 1989;15:54-9.

6 Damkot DK, Pope MH, Lord J, Frymoyer JW. The relationship between work history, work environment and low-back pain in men. Spine 1984;9:395-9.

7 Videman T, Nurminen T, Tola S, Kuorinka I, Vanharanta $H$, Troup JDG. Low-back pain in nurses and some loading factors of work. Spine 1984;9:400-4.

8 Svensson H-O, Andersson GBJ. The relationship of low-back pain, work history, work environment, and stress. Spine 1989;14:517-22.

9 Svensson H-O, Andersson GBJ. Low-back pain in 40- to 47-year-old men: work history and work environment factors. Spine 1983;8:272-6.

10 Pietri F, Leclerc A, Boitel L, Chastang J-F, Morcet J-F, Blondet $M$. Low-back pain in commercial travellers. Scand f Work Environ Health 1992;18:52-8.

11 Magora A. Investigation of the relation between low back pain and occupation: 3. Physical requirements: sitting, standing and weight lifting. Ind Med Surg 1972;41:5-9.

12 Magora A. Investigation of the relation between low back pain and occupation: 6. Medical history and symptoms. Scand F Rehabil Med 1974;6:81-8.

13 Brown JR. Factors contributing to the development of low back pain in industrial workers. Am Ind Hyg Assoc $\mathcal{F} 1975$; 36:26-31.

14 Biering-Sorensen F. A prospective study of low back pain in a general population: I. Occurrence, recurrence and aetiology. Scand $\mathcal{F}$ Rehabil Med 1983;15:71-9.

15 Kelsey JL, Hardy RJ. Driving of motor vehicles as a risk factor for acute herniated lumbar intervertebral disc. $A m \mathcal{F}$ Epidemiol 1975;102:63-73.

16 Kelsey JL, Githens PB, O'Conner T, Weil U, Calogero JA, Holford TR, et al. Acute prolapsed lumbar intervertebral disc: an epidemiologic study with special reference to driving automobiles and cigarette smoking. Spine 1984;9:60813 .

17 Kelsey JL. An epidemiological study of the relationship between occupations and acute herniated lumbar intervertebral discs. Int $\mathcal{F}$ Epidemiol 1975;4:197-204.

18 Nachemsson AL, Elfström E. Intravital dynamic pressure measurements in lumbar discs. A study of common movements, maneuvers and exercises. Scand $f$ Rehabil Med 1970;2(suppl 1):1-4.

19 Kroemer KHE, Robinette JC. Ergonomics in the design of office furniture. Ind Med Surg 1969;38:115-25.

20 Chaffin DB, Park KS. A longitudinal study of low-back pain as associated with occupational weight lifting factors. $\mathrm{Am}$ Ind Hyg Assoc $\mathcal{F}$ 1973;34:513-25.

$21 \mathrm{Xu} \mathrm{Y,} \mathrm{Bach} \mathrm{E,} \mathrm{Ørhede} \mathrm{E.} \mathrm{Occupation} \mathrm{and} \mathrm{risk} \mathrm{for} \mathrm{the} \mathrm{occur-}$ rence of low-back pain (LBP) in Danish employees. Occup Med 1996;46:131-6.

22 Hult L. The Munkfors investigation. Acta Orthop Scand 1954;16(suppl).

23 Hult L. Cervical, dorsal, and lumbar spinal syndromes. Acta Orthop Scand 1954;17(suppl).

24 Ikata T. Statistical and dynamic studies of lesions due to overloading on the spine. Shikoku Acta Med 1965;40:26286.

25 Bongers PM, de Winter CR, Kompier MAJ, Hildebrandt V. Psychosocial factors at work and musculoskeletal disease. Scand F Work Environ Health 1993;19:297-312.

26 Riihimäki $\mathrm{H}$. Low-back pain, its origin and risk indicators. Scand 7 Work Environ Health 1991;17:81-90.

27 Brinck B, Rasmussen NK, Kjøller M, Thomsen LK. Muskel- og skeletsygdom i Danmark (Musculoskeletal diseases in Denmark). DICE (Danish Institute for Clinical Epidemiology), 1995.

28 Coggon D. Questionnaire based exposure assessment methods. Sci Total Environ 1995;168:175-8.

29 Wictorin C, Hjelm E W, Winkel J, Koster M. Reproducibility of a questionnaire for assessment of physical load ducibility of a questionnaire for assessment of physical load during work and

30 Wiktorin C, Selin K, Ekenwall L, Alfredsson L, The Music -Norrtälje Study Group. An interview technique for recording work postures in epidemiological studies. Int $\mathcal{F}$ Epidemiol 1996;25:171-80.

31 Ferguson DA. Strain injuries in hospital employees. Med $\mathcal{f}$ Aust 1970;1:376.

32 Walsh K, Cruddas $M$, Coggon D. Interaction of height and mechanical loading of the spine in the development of lowback pain. Scand $\mathcal{F}$ Work Environ Health 1991;17:420-4.

33 Walsh K, Cruddas M, Coggon D. Low back pain in eight areas of Britain. $\mathcal{F}$ Epidemiol Community Health 1996;46: 227-30.

34 Andersson GBJ. Epidemiologic aspects on low-back pain in industry. Spine 1981;6:53-60.

35 Kottke FJ. Evaluation and treatment of low back pain due to mechanical causes. Arch Phys Med Rehabil 1961;42:42640 . 